\title{
Theoretical Reserve Price in Forestry
}

\author{
Francis Didier Tatoutchoup \\ Department of Economics, Université de Moncton, Moncton, Canada \\ Email: didier.tatoutchoup@umoncton.ca
}

Received 20 June 2016; accepted 8 August 2016; published 11 August 2016

Copyright (C) 2015 by author and Scientific Research Publishing Inc.

This work is licensed under the Creative Commons Attribution-NonCommercial International License (CC

BY-NC).

http://creativecommons.org/licenses/by-nc/4.0/

(c) $\underset{\mathrm{EY}}{\mathrm{N}} \mathrm{NC}$ Open Access

\begin{abstract}
This article uses the forest management problem under uncertainty to derive the optimal reservation price when a standing timber is to be auctioned. Theoretically, the resulting optimal reservation price that considers the harvesting decision is an extended version of Laffont and Maskin's and Riley and Samuelson's reservation price, which is suboptimal in the forestry context.
\end{abstract}

\section{Keywords}

Reserve Price, Auctions, Wicksell Rule, Optimal Forest Rotation, Autoregressive Process

\section{Introduction}

In forestry, the selling of standing timber is conducted either through direct negotiation between the forest owner and the exploiting firm or by auctions. The former is commonly used in Scandinavian countries (Finland, Sweden, and Norway) whereas the latter is popular in countries such as Canada, Great Britain, and the US. For example, the US government agency the United States Forest Service (USFS) uses both first price sealed-bid auctions and ascending auctions for the sale of standing timber. Over the past decade, theoretical and empirical works have focused intensively on these two auction formats by analysing the binding behaviour and the minimum price that must be bid optimally (the optimal reservation price) under various assumptions. Using an independent private value paradigm, [1], [2] determined the optimal reservation in both ascending auctions and first price sealed-bid auctions by assuming that bidders' valuations are exogenous and deterministic. This result is not suitable in forestry, where the valuation of a bidder depends on the optimal harvest time of trees namely, the optimal rotation which is the central problem in the management of forest resources.

This article combines both the auctions and the forest management problem to derive theoretically the optimal reservation price in forestry when the forest owner sells its timber through auctions under uncertainty regarding the stumpage price of timber ${ }^{1}$. The bidder's valuation is endogenous as it depends on the total supply of timber

${ }^{1}$ The forest management problem solves the traditional question in forest economics: When is the best time to cut down a tree or a stand of trees. 
which depends on the optimal cutting age of the tree. Thus, the fixation of a reservation price must take into account the harvesting decision.

In the forest management problem under uncertainty, [3]-[8] showed numerically that, when the stumpage price of timber is uncertain but stationary, the optimal rotation follows a reservation price policy in which the tree is harvested when the current market price of timber is above the historical average or a determined reservation price. Others studies, such as [9]-[11] considered the case of non-stationary price process (geometric Brownian motion). They showed that a reservation price is relevant only if there are fixed costs. All of these studies have implicitly assumed that the forest owner harvests the forest himself by focusing their attention only on the optimal cutting age. In that setting, the reservation price specifies when the forest stand shall be cut or postponed. This article, in addition to the harvesting problem, considers the case where the timber stand is to be auctioned as described above. The participant in the auction must submit a bid higher than the specifying reservation price. The reservation price is set to maximize the expected profit of the forest owner from planting to harvesting. The stumpage prices are assumed to follow a stationary autoregressive process. [12] pointed out that the stumpage market price is best described by a first-order autoregressive process. A stationary autoregressive process has the feature that it is attracted by the long-run mean price (mean-reverting). Therefore, a current market price above the long-run mean price gives higher incentive to the forest owner to harvest the trees earlier.

This article contributes theoretically to the literature of forest auctions by extending the results of Laffont and Maskin as well as Riley and Samuelson in the context of forestry management.

The article is organized as follows. In Section 2, I first present the theoretical model that combines auctions and the forest management problem under uncertainty when stumpage prices follow an autoregressive process. Section 3 then determines the optimal bidding strategies, the optimal cutting age and the optimal reservation price. Finally, Section 4 concludes the article.

\section{Optimal Mechanism}

In this section, I use the forest management framework under uncertainty to derive the theoretical optimal mechanism when a standing timber is sold through auctions. The optimal mechanism consists of the optimal bidding strategy, the optimal cutting age (optimal rotation), and the optimal reservation price. The forest owner is interested in selling the standing timber through auctions because, contrary to direct negotiations, auctions involve competition among buyers, thereby increasing the forest owner's expected revenues, as shown by [13]. I assume that the forest owner cannot harvest the forest himself, as the forest land is publicly owned. The first price sealed-bid auctions and the ascending auctions are used to model the problem because both auction formats are used by USFS for the sale of standing timber. In the US, the forest owner sells only the rights to cut the standing timber, not the forest land itself. In addition, the identity of the winning firm can be different at each harvesting time. Therefore, the best way to address the forest management problem in this situation is the use of the single rotation. This will be assumed in this article.

\subsection{The Model}

Consider a stand of trees with one species. The trees can be the same age or different ages. Let $t$ be the current period, and $t_{\tau}$ the planting time of a tree. The age of the tree at time $t$ is then $\tau=t-t_{\tau}$. The timber growth function denoted by $X(\tau)$ is assumed to be deterministic and depends only on the age of the tree. It is also assumed that $X(\cdot)$ satisfies the following assumptions:

$$
\begin{aligned}
& \text { (i) } X(\cdot) \text { is strictly increasing and twice differentiable, (ii) } \lim _{\tau \rightarrow+\infty} X^{\prime}(\tau)=0 \text {, } \\
& \text { (iii) } \lim _{\tau \rightarrow 0} X(\tau)=0 \text {, and (iv) } g(\tau)=X^{\prime}(\tau) / X(\tau) \text { is decreasing }
\end{aligned}
$$

where $g(\tau)$ is the relative growth rate of timber ${ }^{2}$. Following [3]-[8], [12], I assume that the stumpage prices $\left(P_{t}\right)$ are exogenous and follow an autoregressive process AR(q) that is stationary ${ }^{3}$. I will discuss the case of a random walk process follow. The process is given by:

\footnotetext{
${ }^{2}$ For example, the commonly used exponential growth function $X(\tau)=\mathrm{e}^{a-b / \tau}$, where $a$ and $b$ are positives constant, satisfies these assumptions.

${ }^{3}$ The stumpage price, $P_{t}$, is the price paid for the right to harvest a unit volume of timber from a land.
} 


$$
P_{t}=\mu+\phi_{1} P_{t-1}+\cdots+\phi_{q} P_{t-q}+\xi_{t} ; \quad 0 \leq \phi_{i} \leq 1, i=1, \cdots, q .
$$

The stochastic term $\xi_{t}$ is white noise $\left(E\left[\xi_{t}\right]=0 ; E\left[\xi_{t}^{2}\right]=\sigma^{2} ; E\left[\xi_{t} \xi_{t}^{\prime}\right]=0, \forall t \neq t^{\prime}\right)$. The parameters $\mu, \phi_{i}, i=1, \cdots, q$ are constant.

Let's assume that at each period $t$ there are $N$ potential risk-neutral firms competing for the possession of the standing timber. Prior to the auction, the forest owner announces the total volume of timber $X(\tau)$ to be auctioned as well as the reservation price $R_{t}$ per unit of timber harvested ${ }^{4}$. It is assumed that each firm

$i^{\prime} s \in\{1, \cdots, N\}$ private information is summarized by the realization of a random variable $\theta_{i}$ representing its average cost that is, the exploiting cost per unit of timber harvested ${ }^{5}$. Suppose that each $\theta_{i}$ is drawn independently from the same distribution with the cumulative distribution function $F(\cdot)$ and the density function $f(\cdot)$ on the interval $\left[\theta^{l}, \theta^{h}\right]$. The valuation per unit of volume of timber of firm $i$ at period $t$ is given by:

$$
V_{i t}=P_{t}-\theta_{i} \quad i=1, \cdots, N
$$

where $P_{t}$ is the stumpage price of the timber. I will focus on symmetric equilibria with increasing bids. Let $Y_{i}=\min _{j \neq i} \theta_{j}$; due to symmetry, this function is the same for all bidders (firms). Hence, as denoted by $f_{Y_{1}}(\cdot)$, the density function of $Y_{1}$ is associated with the cumulative distribution function $F_{Y_{1}}(\cdot)$. In a first price sealedbid auction, firm $i$ submits a bid $b_{i t}$ that depends on its signal according to a decreasing function ${ }^{6} \beta_{F t}(\cdot)$ so that $b_{i t}=\beta_{F t}\left(\theta_{i}\right)$. Firm $i$ wins if its bid exceeds the other firms' bids and the reservation price $R_{t}=\beta_{F t}(\delta)$. In first price auctions, the winner is the firm with the lowest cost. It pays its bid according to the equilibrium strategy $\beta_{F t}(\cdot)$. As [14] demonstrated, the first-order condition characterizing the equilibrium bid function is defined by the following differential equation:

$$
\begin{gathered}
\beta_{F t}^{\prime}\left(\theta_{i}\right)=-f_{Y_{1}}\left(\theta_{i}\right)\left[V_{i t}\left(\theta_{i}\right)-\beta_{F t}\left(\theta_{i}\right)\right] /\left(1-F_{Y_{1}}\left(\theta_{i}\right)\right), \text { if } \theta_{i} \leq \delta \\
\beta_{F t}(\delta)=R_{t}=P_{t}-\delta .
\end{gathered}
$$

The dominant strategy for each firm in an ascending auction is to reveal its private value $b_{i t}=V_{i t}$, because it pays the second highest bid when it wins. Therefore, the equilibrium bidding strategy in an ascending auction is defined by:

$$
\begin{aligned}
& \beta_{A t}\left(\theta_{i}\right)=V_{i t}=P_{t}-\theta_{i}, \quad i=1, \cdots, N . \\
& \beta_{A t}(\delta)=R_{t}=P_{t}-\delta .
\end{aligned}
$$

In the first price auctions, the expected payment of a firm with cost parameter $\theta_{i} \leq \delta$ is $\beta_{F t}\left(\theta_{i}\right)\left(1-F_{Y_{1}}\left(\theta_{i}\right)\right)$. Therefore the expected revenue to the forest owner from the auction is $L_{t}(\tau, \delta)=N X(\tau) \int_{\theta^{l}}^{\delta} \beta_{F t}(\theta)\left(1-F_{Y_{1}}(\theta)\right) f(\theta) \mathrm{d} \theta$. After some algebraic manipulation, this becomes:

$$
L_{t}(\tau, \delta)=\left(P_{t} A_{1}(\delta)-A_{2}(\delta)\right) X(\tau)
$$

where $A_{1}(\delta)=1-(1-F(\delta))^{N}$, and $A_{2}(\delta)=N \delta\left(1-F_{Y_{1}}(\delta)\right) F(\delta)+N \int_{\theta^{l}}^{\delta} \theta F(\theta) f_{Y_{1}}(\theta) \mathrm{d} \theta$. The problem of the forest owner can now be written as:

$$
\begin{array}{ll}
\max _{\tau \geq 0, \delta \in\left[\theta^{l}, \theta^{h}\right]} & W_{t}(\tau, \delta)=\mathrm{e}^{-r \tau} L_{t}(\tau, \delta)-K \\
\text { s.t } & R_{t}=P_{t}-\delta \geq 0 \\
& P_{t}=\mu+\phi_{1} P_{t-1}+\cdots+\phi_{q} P_{t-q}+\xi_{t} ; 0 \leq \phi_{i} \leq 1, i=1, \cdots, q
\end{array}
$$

where $K$ is the planting cost, $\tau$ and $\delta$ are the choice variables, and $W_{t}(\tau, \delta)=\mathrm{e}^{-r \tau} L_{t}(\tau, \delta)-K$ represents the present value of the forest owner's profit since the planting date $t_{\tau}$ where $\mathrm{e}^{-r \tau}$ is the discount factor (recall that $\tau=t-t_{\tau}$ ).

\footnotetext{
${ }^{4}$ Because firms are risk neutral, the total volume supplied by the forest owner will be the total volume sold.

${ }^{5}$ I suppose that the total cost includes the logging cost, the hauling cost, and the road construction cost as well as other non-observable costs.

${ }^{6}$ The subscript Ft refers to the equilibrium in the first price auctions and, as presented later, the subscript At refers to the equilibrium in the ascending auction.
} 


\subsection{The Optimal Mechanism}

To solve problem (8), I first derive the optimal rotation $\tau$ as a function of the cut-off cost $\delta$. Following [15], the intertemporal arbitrage equilibrium condition for stumpage is:

$$
L_{t}=\mathrm{e}^{-r} E_{t}\left[L_{t+1} \mid P_{t}, \cdots, P_{0}\right] .
$$

As $E_{t}\left[P_{t+1} \mid P_{t}, P_{t-1}, \cdots, P_{0}\right]=\mu+\phi_{1} P_{t}+b$ where $b=\phi_{2} P_{t-1}+\cdots+\phi_{q} P_{t+1-q}$, and substituting $L_{t}$ and $L_{t+1}$ into (9), the rotation satisfies:

$$
g(\tau)=r+\log \frac{P_{t} A_{1}(\delta)-A_{2}(\delta)}{\left(b+\mu+\phi_{1} P_{t}\right) A_{1}(\delta)-A_{2}(\delta)} .
$$

Equation (10) is an extension of [15] that considers competition among potential harvesting firms. Let $\Gamma$ be the family of $\delta \in\left[\theta^{l}, \theta^{h}\right]$ such that the solution of Equation (10) exists. $\Gamma$ is non-empty if and only if the current price is sufficiently high such that it is at least higher than $P^{l}$ given by ${ }^{7}$

$$
P^{l}=\frac{(\mu+b) \mathrm{e}^{-r}}{1-\phi_{1} \mathrm{e}^{-r}} .
$$

The price $P^{l}$ is called the reservation price in the literature of the harvesting problem under uncertainty with stationary prices, as presented in Section 1 . Thus, cutting takes place only if the current price is above $P^{l}$. The minimum price $P^{l}$ depends only on past prices and does not depend on the cutting age. This is the first time that an analytical expression of the reservation price has been derived, and it is consistent with previous numerical results. For example [4] used simulation to demonstrate that the reservation price when the price process is stationary depends on past prices and is almost invariant with respect to the optimal cutting age.

Now let's find the optimal rotation and the optimal reservation price when the auction takes place in other words, the forest owner finds it optimal to allow the harvest of the forest stand. This decision occurs when $P_{t} \geq P^{l}$. Thus, $\Gamma$ is non-empty and $\tau=\tau(\delta)$ is an implicit function of $\delta$. Substituting sinto problem (8) and solving for $\delta$, it follows from the extreme value theorem that the problem has a solution. Therefore, the first order condition for optionality given by $\frac{\mathrm{d} W}{\mathrm{~d} \delta}=0$ implies: $^{8}$

$$
(g(\tau)-r)\left(P_{t} A_{1}(\delta)-A_{2}(\delta)\right) \frac{\mathrm{d} \tau}{\mathrm{d} \delta}+\frac{\mathrm{d}\left(P_{t} A_{1}(\delta)-A_{2}(\delta)\right)}{\mathrm{d} \delta}=0 .
$$

Denoted by $R_{t}^{*}=P_{t}-\delta^{*}$, the optimal reservation price where the optimal cut-off cost $\delta^{*}$ satisfies Equation (12). Equation (12) deserves some comments. When the volume of timber is exogenous, as assumed in previous studies, the optimal rotation is independent of the cut-off $\operatorname{cost} \delta(\mathrm{d} \tau / \mathrm{d} \delta=0)$, implying that the first term of Equation (12) is zero. Thus, Equation (12) becomes:

$$
P_{t}-\delta-\frac{F(\delta)}{f(\delta)}=0
$$

Denoted by $R_{t}^{0}=P_{t}-\delta^{0}$, the Laffont and Maskin and Riley and Samuelson ([1], [2] reservation price, where $\delta^{0}$ satisfies (13). As shown in the Appendix, the optimal reservation $R_{t}^{*}$ exists and satisfies $R_{t}^{*}>R_{t}^{0}>0$. The illustration is given in Figure 1.

Clearly, in the context of forestry, Laffont and Maskin's and Riley and Samuelson's result is suboptimal. Finally, the optimal rotation $\tau^{*}$ is implicitly determined by Equation (10) with $\delta=\delta^{*}$. The optimal rotation $\tau^{*}$ clearly depends on the current price and defines the supply curve of timber, which has a positive slope. Indeed, differentiation $\tau^{*}$ with respect to $P_{t}$ gives:

${ }^{7} P^{l}$ is determined by solving Equation (10) when $\delta=\theta^{l}$. The solution of Equation (10) exists if and only if $g(\tau) \geq 0$. Also note that $\delta=\theta^{l}$ refers to the case where there is no auction.

${ }^{8}$ Since $\tau$ depends on $\delta, \frac{\mathrm{d} W}{\mathrm{~d} \delta}=\frac{\partial W}{\partial \tau} \frac{\mathrm{d} \tau}{\mathrm{d} \delta}+\frac{\partial W}{\partial \delta}$. Or $\frac{\partial W}{\partial \delta}=\mathrm{e}^{-r \tau} X(\tau) \frac{\mathrm{d}\left(P_{t} A_{1}(\delta)-A_{2}(\delta)\right)}{\mathrm{d} \delta}$, and

$\frac{\partial W}{\partial \tau}=\mathrm{e}^{-r \tau} X(\tau)(g(\tau)-r)\left(P_{t} A_{1}(\delta)-A_{2}(\delta)\right)$. 


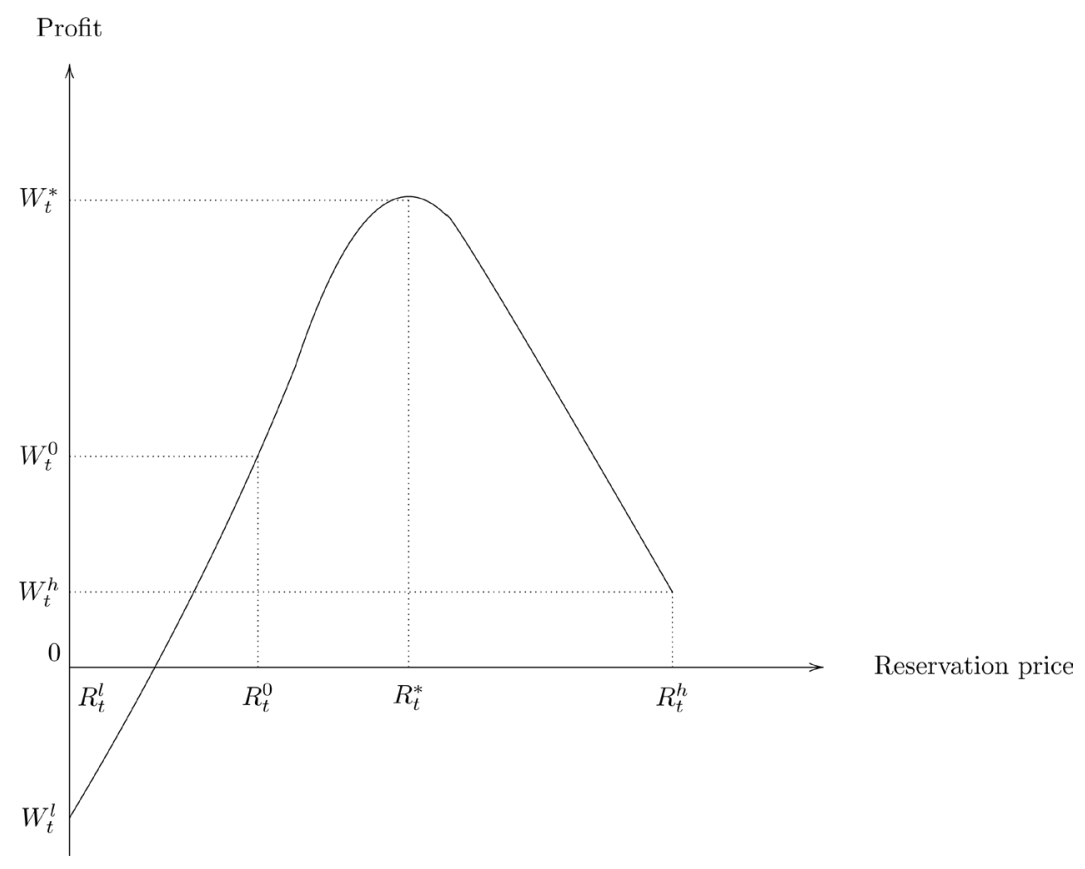

Figure 1. Profit curve.

$$
\frac{\mathrm{d} \tau^{*}}{\mathrm{~d} P_{t}}=\frac{\left(1-\phi_{1} \mathrm{e}^{g\left(\tau^{*}\right)-r}\right) A_{1}\left(\delta^{*}\right)}{g^{\prime}\left(\tau^{*}\right) \mathrm{e}^{g\left(\tau^{*}\right)-r}\left(\left(b+\mu+\phi_{1} P_{t}\right) A_{1}\left(\delta^{*}\right)-A_{2}\left(\delta^{*}\right)\right)}<0 .
$$

Equation (14) means that, as the stumpage price increases, the new rotation is shorter than the old rotation. This leads to "over-mature" timber that will be cut, thereby increasing the volume of timber and hence the supply.

The previous results were obtained under the assumption that the stumpage price process follows a stationary autoregressive process. If, for example, stumpage prices follow a random walk without drift ${ }^{9}$, the best prediction of the future price is the current price. It follows from the arbitrage equilibrium condition (9) that the optimal rotation is independent of the reservation price and satisfies the well-known Wicksell rule that states the timber will be cut when its relative growth equals the interest rate $(g(\tau)=r)$. The supply of the timber is then perfectly inelastic. As a result, the optimal reservation is the same as the findings of Laffont and Maskin as well as Riley and Samuelson.

\section{Conclusion}

This article combines auctions and the forest management problem to analyse the optimal reservation price in a forest when auctions are used to sell standing timber under uncertain prices by assuming that the price process follows an autoregressive model. The analytical results show that the decision of the forest owner is to auction the standing timber when the current price is higher than a minimum price level that is invariant over time but depends on the parameters of the process. Therefore, to maximise profits, the forest owner will set a reservation that takes into account the optimal harvest time. This optimal reservation price is an extended version of Laffont and Maskin and Riley and Samuelson reservation price ([1], [2]), which is suboptimal in the context of forest management and lower than the derived optimal reservation price.

\section{Acknowledgements}

We thank the editor and the referee for their comments.

${ }^{9} \mathrm{~A}$ random walk without drift is given by $P_{t}=P_{t-1}+\xi_{t}$, where $\xi_{t}$ is white noise. 


\section{References}

[1] Laffont, J.J. and Maskin, E. (1980) Optimal Reservation Price in the Vickrey Auction. Economics Letters, 6, 309-313. http://dx.doi.org/10.1016/0165-1765(80)90002-6

[2] Riley, J.G. and Samuelson, W.F. (1981) Optimal Auctions. The American Economic Review, 71, 381-392.

[3] Brazee, R. and Mendelsohn, R. (1998) Timber Harvesting with Fluctuating Prices. Forest Science, 34, 359-372.

[4] Haight, R.G. and Holmes, T.P. (1991) Stochastic Price Models and Optimal Tree Cutting: Results from Loblolly Pine. Natural Resource Modeling, 5, 423-443.

[5] Haight, R.G. and Smith, W.D. (1991) Harvesting Loblolly Pine Plantations with Hardwood Competition and Stochastic Prices. Forest Science, 37, 1266-1282.

[6] Lohmander, P. (1988) Pulse Extraction under Risk and a Numerical Forestry Application. Systems Analysis, Modeling, and Simulation, 5, 339-354.

[7] Norstrom, C.J. (1975) A Stochastic Model for the Growth Period Decision in Forestry. Swedish Journal of Economics, 77, 329-337. http://dx.doi.org/10.2307/3438965

[8] Plantinga, A.J. (1998) The Optimal Rotation Decision: An Option Value Approach. Forest Science, 44, $192-202$.

[9] Clarke, H.R. and Reed, W.J. (1989) The Tree-Cutting Problem, in a Stochastic Environment: The Case of Age-Dependent Growth. Journal of Economic Dynamics and Control, 13, 569-595. http://dx.doi.org/10.1016/0165-1889(89)90004-3

[10] Morck, R., Schwartz, E. and Stangeland, D. (1989) The Valuation of Forestry Resources Under Stochastic Prices and Inventories. Journal Financial and Quantitative Analysis, 24, 473-487. http://dx.doi.org/10.2307/2330980

[11] Thomson, T.A. (1992) Optimal Forest Rotation When Stumpage Prices Follow a Diffusion Process. Land Economics, 68, 329-342. http://dx.doi.org/10.2307/3146380

[12] Washburn, C.L. and Binkley, C.S. (1990) Informational Efficiency of Markets for Stumpage. American Journal of Agricultural Economics, 72, 394-405. http://dx.doi.org/10.2307/1242342

[13] Tatoutchoup, F.D. (2015) Optimal Forestry Contract under Asymmetry of Information. Scandinavian Journal of Economics, 117, 84-107. http://dx.doi.org/10.1111/sjoe.12083

[14] Milgrom, P. and Weber, R. (1982) A Theory of Auctions and Competitive Bidding. Econometrica, 50, 1089-1122. http://dx.doi.org/10.2307/1911865

[15] Washburn, C.L. and Binkley, C.S. (1993) Informational Efficiency of Markets for Stumpage: Reply. American Journal of Agricultural Economics, 75, 239-242. http://dx.doi.org/10.2307/1242973 


\section{Appendix}

\section{Existence of the Optimal Reservation Price}

Recall that the optimal reservation price is $R_{t}^{*}=P_{t}-\delta^{*}$ where $\delta^{*}$ satisfies Equation (12). This equation can rewritten as

$$
\psi(\delta)=(g(\tau)-r)\left(P_{t} A_{1}(\delta)-A_{2}(\delta)\right) \frac{\mathrm{d} \tau}{\mathrm{d} \delta}+\left\{P_{t} A_{1}^{\prime}(\delta)-A_{2}^{\prime}(\delta)\right\}=0
$$

where $\left(\mathrm{d} W_{t}(\tau, \delta) / \mathrm{d} \delta\right)=X(\tau) \mathrm{e}^{-r \tau} \psi(\delta)$, so that $\left(\mathrm{d} W_{t} / \mathrm{d} \delta\right) \geq 0 \Leftrightarrow \psi(\delta) \geq 0$. I also have that,

$$
\begin{aligned}
& A_{1}^{\prime}(\delta)=N f(\delta)(1-F(\delta))^{N-1}, A_{2}^{\prime}(\delta)=N\left(1-F_{Y_{1}}(\delta)\right)(F(\delta)+\delta f(\delta)) \text {, and } \\
& \frac{\mathrm{d} \tau}{\mathrm{d} \delta}=-\frac{\mathrm{e}^{g(\tau)-r}\left(\left(b+\mu+\phi_{1} P_{t}\right) A_{1}^{\prime}(\delta)-A_{2}^{\prime}(\delta)\right)-\left(P_{t} A_{1}^{\prime}(\delta)-A_{2}^{\prime}(\delta)\right)}{g^{\prime}(\tau) \mathrm{e}^{g(\tau)-r}\left(\left(b+\mu+\phi_{1} P_{t}\right) A_{1}(\delta)-A_{2}(\delta)\right)}
\end{aligned}
$$

Let $\delta^{0}$ be the solution of Equation (13), then $P_{t} A_{1}^{\prime}\left(\delta^{0}\right)-A_{2}^{\prime}\left(\delta^{0}\right)=0$. It follows from Equation (16) that $\tau^{\prime}\left(\delta^{0}\right)=-\left(b+\mu+\left(\phi_{1}-1\right) P_{t}\right) A_{1}^{\prime}\left(\delta^{0}\right) /\left(g^{\prime}\left(\tau^{0}\right)\left(\left(b+\mu+\phi_{1} P_{t}\right) A_{1}(\delta)-A_{2}(\delta)\right)\right)$ where $\tau^{0}=\tau\left(\delta^{0}\right)$. From Equation (10) I obtain, $g(\tau)-r \geq 0 \Leftrightarrow b+\mu+\left(\phi_{1}-1\right) P_{t} \leq 0$ implying that $(g(\tau)-r)\left(b+\mu+\left(\phi_{1}-1\right) P_{t}\right)<0$. Hence,

$$
\psi\left(\delta^{0}\right)=-\frac{\mathrm{e}^{g\left(\tau^{0}\right)-r}\left(b+\mu+\left(\phi_{1}-1\right) P_{t}\right) A_{1}^{\prime}\left(\delta^{0}\right)\left(P_{t} A_{1}\left(\delta^{0}\right)-A_{2}\left(\delta^{0}\right)\right)}{g^{\prime}\left(\tau^{0}\right)\left(\left(b+\mu+\phi_{1} P_{t}\right) A_{1}(\delta)-A_{2}(\delta)\right)}<0 .
$$

I also have

$$
\psi\left(\theta^{l}\right)=N f\left(\theta^{l}\right)\left(P_{t}-\theta^{l}\right)>0 .
$$

It follows from Equation (18) and Equation (17) that $\psi\left(\theta^{l}\right) \psi\left(\delta^{0}\right)<0$. The intermediate value theorem implies that there exist $\delta^{*} \in\left(\theta^{l}, \theta^{0}\right)$ such that $\psi\left(\delta^{*}\right)=0$. Thus, $R_{t}^{*}>R_{t}^{0}>0$.

\section{Submit or recommend next manuscript to SCIRP and we will provide best service for you:}

Accepting pre-submission inquiries through Email, Facebook, LinkedIn, Twitter, etc.

A wide selection of journals (inclusive of 9 subjects, more than 200 journals)

Providing 24-hour high-quality service

User-friendly online submission system

Fair and swift peer-review system

Efficient typesetting and proofreading procedure

Display of the result of downloads and visits, as well as the number of cited articles

Maximum dissemination of your research work

Submit your manuscript at: http://papersubmission.scirp.org/ 